\title{
La condición de doble periferia en unidades subestatales
}

\author{
A condição de dupla periferia nas unidades subestatais
}

\section{The condition of double periphery in substate units}

\section{La condition de double périphérie en unités sub-étatiques}

\author{
Stella Maris Juste ${ }^{1}$ \\ Recebido em 12/04/2017; revisado e aprovado em 18/06/2017; aceito em 21/06/2017 \\ DOI: http://dx.doi.org/10.20435/inter.v18i4.1582
}

\begin{abstract}
Resumen: El presente artículo investigativo se propone un acercamiento teórico al concepto de doble periferia como el condicionamiento que determina la gestión internacional de algunas unidades subestatales Tal condicionamiento se circunscribe a las circunstancias ambientales, económicas y políticas que determinan un entorno desde el cual los departamentos, regiones, provincias, municipios, alcaldías, landers, entre otros, se sitúan y despliegan su accionar internacional respecto del Estado del cual forman parte, y respecto del sistema internacional. En el presente estudio se tomarán como casos la provincia de Jujuy (Argentina), el departamento de Tarija (Bolivia) y la región de Tarapacá (Chile). La existencia de asimetrías en el sistema internacional y en el interior de los Estados lleva a pensar en estructuras que condicionan y caracterizan el accionar internacional de diversos actores, siendo las unidades subestatales el centro de este estudio. La situación de doble periferia es el marco desde el cual las unidades subestatales despliegan su gestión internacional en búsqueda de oportunidades que permitan superar los condicionamientos estatales y sistémicos.
\end{abstract}

Palabras clave: Estado; unidades subestatales; centro; periferia; doble periferia.

Resumo: A presente investigação propõe uma aproximação teórica ao conceito de dupla periferia como o condicionamento que determina a gestão internacional de algumas unidades subestatais. Tal condicionamento circunscreve às circunstâncias ambientais, econômicas, e políticas que determinam um ambiente desde o qual os departamentos, regiões, províncias, municípios, prefeituras, landers, entre outros, situam-se e empregam seu acionar internacional respeito do estado do qual formam parte, e respeito do sistema internacional. Na presente pesquisa se pegaram como casos a província de Jujuy (Argentina), o departamento de Tarija (Bolívia) e a região de Tarapacá (Chile). A existência de assimetrias no sistema internacional e no interior dos estados leva pensar em estruturas que condicionam e caracterizam o acionar internacional dos diversos atores, sejam as unidades subestatais o centro desta pesquisa. A situação de dupla periferia é o cenário desde quais as unidades subestatais empregam sua diligência internacional na procura de oportunidades que permitam superar os condicionamentos estatais e sistêmicos.

Palavras-chave: Estado; unidades subestatais; centro; periferia; dupla periferia.

Abstract: The purpose of this article is to make a theoretical approach to the double periphery concept, as a restriction which determines international management in some substate units. Double periphery condition is connected to the environment, economy and politics which define a framework from where departaments, regions, provinces, municipalities, landers, and other, deploy its international management. The present study will focus of three cases: the province of Jujuy (Argentina), the department of Tarija (Bolivia) and the region of Tarapacá (Chile). The asymmetries in the international system and inside the State show the existence of structures which determine and characterize the international action of many actors, like the substate units. The double periphery situation is the framework from where substate units deploy its international management looking for new development opportunities in order to get over these restrictions.

Key words: State; substate units; center; periphery; double periphery.

Résumé: Cet article a pour but de réaliser un approche théorique au concept de double périphérie comme de condition qui excerse une influence sur la gestión internationale de certains unités sub-étatiques. Cette condition se réfère à les facteurs environnementaux, économiques y politiques quiqui déterminent un environnement à partir duquel les departaments, regions, provinces, et municipalités, landers, entre outres, déploient leur gestion internationale. Cette étude prendre comme des cas d'étude: la province de Jujuy (Argentina), le depertament de Tarija (Bolivie) et la región de Tarapacá (Chili). L'existence d'asymétries dans

\footnotetext{
${ }^{1}$ Consejo Nacional de Investigaciones Científicas y Técnicas (CONICET), Buenos Aires, Argentina; Universidad Nacional de Jujuy (UNJu), San Salvador de Jujuy, Argentina.
} 
le système international et à l'intérieur des États manifestent structures qui conditionnet et caractérisaient l'action international de différents acteurs, dans cette cas, les unités sub-étatiques. La situation de doublé périphérie est le cadre à partir duquel les unités sub-étatiques déploient leur gestion international dans la quête des opportunitiés de dépasser les facteurs déterminants étatiques et systèmeques.

Mots-clés: État; unités subétatiques; centre, périphérie, double périphérie.

\section{INTRODUCCIÓN}

En el campo de las Relaciones Internacionales múltiples teorías abordaron la estructura y funcionamiento del sistema internacional en referencia a sus actores, procesos y vinculaciones. Immanuel Wallerstein (1979) lo hizo a través del planteamiento de la existencia del SistemaMundo, concebido como una estructura con fronteras, estructura, grupos y un conjunto de normas que la legitiman y le brindan coherencia (WALLERSTEIN, 1979, p. 490 y ss).

Desde esta mirada los Estados situados en el centro aglutinan el capital, ostentan el desarrollo de tecnología, producen manufacturas complejas, compran materias y bienes primarios de las zonas periféricas, son sociedades de alto consumo, y en lo político representan fuertes actores capaces de ejercer influencia en el sistema (WALLERSTEIN, 1979, p. 491-3). En el extremo opuesto se ubica la periferia, que reúne a las regiones de economías primarias y manufacturas poco elaboradas, son economías orientadas a la exportación, y que suplen las necesidades del centro del sistema, mientras que en lo político son sociedades a las que se les ha impuesto la organización estatal-nacional de forma externa a la realidad social preexistente, haciendo de ellas Estados débiles y que por lo general, son Estados que han logrado su independencia luego ser colonia de una potencia (WALLERSTEIN, 1979, p. 492). Aquí se ubican gran parte de los Estados latinoamericanos y africanos, y entre ellos se sitúan los Estados cuyas unidades subestatales forman parte de este estudio

En América Latina la Comisión Económica para América Latina y el Caribe (CEPAL) buscó explicar el atraso de los Estados económicos a través de las debilidades que en ellos existían para su modernización y que impedían su progreso económico. La dinámica del sistema mundial era definida por el patrón de desarrollo dominante que establece condiciones de desarrollo en el centro y subdesarrollo en la periferia (SUNKEL; PAZ, 1970, p. 69; PREBISCH, 2008, p. 28-9; FERRER, 2010, p. 9-10). De acuerdo a esta lógica, las actividades más avanzadas se concentran en el centro, donde existe una creciente demanda de exportaciones y las condiciones para el desarrollo son más favorables. En la periferia en cambio, los actores se adaptan a las demandas del centro que condicionan su desarrollo, estableciéndose una relación de dependencia y dominación (SUNKEL; PAZ, 1970, p. 62-7).

Con este marco contextual, la presente investigación se propone indagar las condiciones de dependencia política de determinadas unidades subestatales, respecto del Estado que forman parte y respecto de la inserción de ese Estado en el Sistema Internacional. Esta condición de dependencia influye en la asignación de roles entre las unidades subestatales de un Estado, condicionando el desarrollo de las mismas.

A fin de analizar esta dependencia se plantean dos objetivos específicos. El primero de ellos es analizar la inserción periférica de los Estados en el Sistema Internacional. Esta relación de dependencia es la primera periferia del estudio de la presente investigación. Luego, el segundo objetivo específico se propone examinar como la inserción periférica de los Estados se reproduce en el interior del mismo. 
La hipótesis de partida señala que la inserción periférica de algunos Estados en el sistema internacional, se reproduce hacia el interior de las fronteras estatales, favoreciendo la aparición de unidades subestatales de centro y unidades subestatales periféricas. A partir de allí, pueden identificarse unidades subestatales de doble periferia, es decir, periféricas respecto del Estado que forman parte, y respecto del Sistema Internacional.

Para corroborar la existencia de esta situación de doble periferia se analizarán los casos de la provincia de Jujuy (Argentina), la región de Tarapacá (Chile) y el departamento de Tarija (Chile).

\section{LA PRIMERA PERIFERIA: ESTADO - SISTEMA INTERNACIONAL}

La corriente estructuralista o desarrollista se consolidó como visión centro-periférica a partir del célebre estudio de la CEPAL titulado "El desarrollo económico de América Latina y sus principales problemas", de Raúl Prebisch (1949). Entre los años 1950 y 1960 el estructuralismo se convirtió en la herramienta analítica para interpretar la distribución de los incrementos de productividad que derivaban del cambio técnico y la acumulación del capital, y elaborar una concepción del desarrollo de alcance mundial² (BETETA; MORENO-BRID, 2012, p. 79).

El estructuralismo se destacó por aportar una visión para el desarrollo que tomara en cuenta parámetros no económicos de los modelos macroeconómicos latinoamericanos (BETETA; MORENO-BRID, 2012, p. 77-8; BRICEÑO RUIZ; QUINTERO RIZZUTO; RUIZ DE BENÍTEZ, 2013, p. 5-6). Esta observación es particularmente pertinente con respecto a sistemas económicos heterogéneos, social y tecnológicamente, como sucede con las economías latinoamericanas en estudio. Su máximo exponente, Prebisch (1979) estudió el sistema internacional a partir del planteo de la existencia de una estructura jerárquica que moldea Estados y regiones, distinguiendo diferentes niveles de desarrollo entre el centro y periferia de las sociedades. En él, las disparidades tienen su origen tanto en las relaciones interregionales como en la dinámica interna de la periferia, siendo las regiones centro los subsistemas de la sociedad organizados sobre una base territorial con capacidad para generar y absorber cambios innovadores, mientras que las regiones periféricas son subsistemas cuya senda de desarrollo está determinada por las características de la región centro con respecto a la cual se encuentran en una relación básica de dependencia (PREBISCH, 1979, p. 493).

A partir de su conquista, América Latina se insertó al sistema internacional desde una situación de subordinación respecto de las economías imperantes del momento, hecho que se profundizó con la complejización del sistema y el impacto de los avances en la tecnología que más tarde desembocaría en el proceso de la globalización (FERRER, 2007, p. 431-2; 2010, p. 8). Los problemas de la globalización son ya conocidos, la región no logró transformar su estructura económico-productiva para asimilar la revolución tecnológica de forma positiva y lograr que los Estados latinoamericanos pudieran insertarse en la economía internacional desde una mejor posición (FERRER, 2010, p. 9). Entonces cabe preguntarnos, ¿cuáles son las características que presentan Argentina, Bolivia y Chile y que definen su pertenencia a la periferia del sistema internacional según los planteamientos estructuralistas?

\footnotetext{
${ }^{2}$ En América Latina el estructuralismo fue el modelo que explicó y justificó el patrón de relaciones entre los países considerados desarrollados y aquellos en vías de desarrollo. Aquí, el subdesarrollo no es considerado como un estado, sino como un proceso, siendo ambos extremos (centro y periferia) parte de un mismo sistema de relaciones (SUNKEL; PAZ, 1970, p. 32).
} 


\section{- Argentina (1994-2015)}

La década del noventa significó para Argentina los años del "transformismo" con un profundo proceso de reformas marcado por el predominio del capital financiero y del agronegocio, que prosiguió con una decadencia de la protección social y un proceso de desindustrialización hasta la crisis del año 2001 (FERRER, 2010, p. 12-3; DOMINGUES, 2012, p. 33). El modelo neoliberal fue llevado a su límite y las consecuencias fueron extremas para la economía que se recuperó gradualmente a través de la exportación de commodities primarias (especialmente la soja), "con la subordinación de los pequeños y medianos productores a las empresas transnacionales del sector, además de la expansión sistemática de la gran minería" (DOMINGUES, 2012, p. 34). Los años posteriores a la crisis, el Estado tuvo el mejor desempeño en la región en reducir la pobreza e impulsar la prosperidad entre 2004 y 2008, tendencia que disminuyó gradualmente después de 2008 (ARGENTINA, 2015).

El sector externo también ha sido reflejo de los distintos problemas internos que aquejaron a Argentina durante el periodo estudiado. Desde el año 2008 la inflación interna agravó la pérdida de competitividad de la producción y coadyuvó al deterioro del mercado de exportación, hecho que se sumó a la imposibilidad de financiarse en el exterior y las limitadas inversiones externas receptadas $^{3}$ (FONDO MONETARIO INTERNACIONAL [FMI], 2016, p. 5-6).

En el comercio regional el Mercado Común del Sur (MERCOSUR) es su principal socio, habiendo concentrado el $24 \%$ de las exportaciones argentinas y el $23 \%$ de las importaciones en 2015 (CÁMARA ARGENTINA DE COMERCIO Y SERVICIOS, 2016). Respecto al comercio por países para el mismo año, el principal socio es Brasil, seguido de China, Estados Unidos y Chile (CÁMARA ARGENTINA DE COMERCIO Y SERVICIOS, 2016). Al final del periodo de estudio, el año 2015, el PBI registrado fue 583.2 mil millones de dólares, observándose un crecimiento del 2,4\% respecto del año anterior (BANCO MUNDIAL, 2016a).

A nivel político el inicio del kirchnerismo en 2003 marcó un fuerte liderazgo personalista y un discurso antiestadounidense, al que luego se agregó al rechazo por el FMI (DABAT, 2012 , p. 45-6) y la ruptura con el neoliberalismo. Este cambio coincidiría con el proceso regional sudamericano de integración que marcaría una nueva forma de reinserción de corte más nacionalista y un claro acercamiento a gobiernos personalistas como Venezuela (DABAT, 2012, p. 46). No obstante ello, Argentina continuó dependiente de las exportaciones primarias y del capital extranjero, donde el Estado desempeña un rol central ${ }^{4}$ en la economía aunque el modelo de desarrollo siga indefinido y los esfuerzos por consolidar acuerdos en el sector agropecuario sean débiles (DOMINGUES, 2012, p. 34). Así y todo el campo domina la economía argentina, mientras la actividad minera avanza lentamente y el sector industrial se encuentra poco desarrollado.

\footnotetext{
${ }^{3}$ El acceso a fondos de inversión (holdouts) internacional estuvo limitado por las negativas de renegociación con los acreedores que dificultó la inversión externa durante la administración kirchnerista, situación que se revirtió con el cambio de administración a finales de 2015 el cual supuso el acuerdo con los fondos de inversión tenedores de deuda argentina (FMI, 2016, p. 6-8).

${ }^{4}$ En febrero de 2017, los datos de acceso al agua potable y saneamiento que miden el desarrollo de infraestructura sanitaria del país ubican a Argentina por detrás de sus pares de la región Brasil, Chile y Uruguay (AGUA POTABLE..., 2017).
} 


\section{- Chile (1991-2015)}

En el año 1990 Chile retornó a la democracia de la mano del presidente Aylwin quien encabezó una transición política recordada por excelentes resultados económicos (GRAN LOGRO..., 2016). A través de una serie de reformas que incluyeron la modificación del sistema tributario y laboral, sumado a un contexto internacional favorable, propiciaron el crecimiento del 7,3\% de la economía chilena en el periodo 1990-19945 (BANCO MUNDIAL, 2016b).

El país ha sido otro ejemplo en la región de la aplicación del modelo neoliberal y de la idea de explotación de las "ventajas comparativas" de su economía nacional centrada en productos primarios (DOMINGUES, 2012, p. 34). No obstante, la debilidad derivada de la escasa diversificación productiva del país se vio reflejada con la crisis asiática de 1997, conocida como la "crisis de la tercera generación" (COCCARO, 2006, s.d.). Como consecuencia, los principales socios asiáticos redujeron sus importaciones e inversión en la región, produciéndose un déficit comercial con China, Japón y Corea, y debiendo sobrellevar la caída del precio del cobre y el valor exportado (CEPAL, 1998 , p. 17; COCCARO, 2006, s.d.). Esta situación condujo a una retracción directa del PBI chileno durante los próximos tres años (CEPAL, 1998, p. 26) demostrando además, como la apertura a capitales externos incrementaba la vulnerabilidad del país y la exposición a los shocks externos (COCCARO, 2006, s.d.; ORGANIZACIÓN PARA LA COOPERACIÓN Y EL DESARROLLO ECONÓMICO [OCDE], 2013, p. 3).

A partir del 2000 Chile continuó apostado a una economía abierta a los flujos de capitales, pero al mismo tiempo construyó fuertes instituciones para enfrentar los riesgos asociados, sin grandes cambios en su matriz productiva. La economía registró una desaceleración en el 2014 con un crecimiento del 1,9\% afectada por un retroceso en el sector minero debido al fin del ciclo de inversión, la caída de los precios del cobre y el declive en el consumo privado (BANCO MUNDIAL, 2016b).

Aunque los informes de la OCDE describen a Chile como un Estado que ha conseguido impresionantes avances hacia una mayor prosperidad económica y reducción de la pobreza, sosteniendo el ingreso per cápita más elevado de América Latina durante los últimos años (OCDE, 2013 , p. 4), su dependencia a la exportación de bienes primarios es uno de los principales obstáculos a superar (CEPAL, 1998, p. 7).

A pesar de los indicadores antes mencionados hay muchas razones que retienen a Chile en la periferia de la economía mundial. Una de esas razones es su dependencia de los recursos naturales, específicamente del cobre que representa más de la mitad de sus exportaciones ${ }^{6}$ (OCDE, 2013, p. 4-5). La minería sigue siendo un negocio muy rentable y continúa atrayendo importantes entradas de IED, convirtiéndolo así en un sector importante y tradicional para la economía. No obstante, la pérdida de competitividad a causa del incremento de los costos laborales y energéticos, resulta preocupante (CHILE, 2015a, p. 17). La solidez del crecimiento de Chile depende fundamentalmente de la demanda mundial, en especial de China, que constituye el principal mercado de exportación de materias primas chilenas (OCDE, 2013, p. 9-10).

\footnotetext{
${ }^{5}$ Chile es una economía relativamente pequeña si se considera su población de casi 18 millones de personas y un PBI de 240,1 mil millones de dólares en 2014 (BANCO MUNDIAL, 2016a).

${ }^{6}$ Además de la producción cuprífera, Chile es el segundo mayor productor de salmón del mundo y el cuarto mayor exportador de vino (OCDE, 2013, p. 4-5).
} 
Con todo ello Chile continua siendo un referente regional de progreso y políticas públicas de innovación y transparencia, pero enfrenta desafíos estructurales que le permitan impulsar la productividad y superar su dependencia a las exportaciones de cobre y al mismo tiempo, generar políticas de crecimiento más inclusivas tendientes a reducir la desigualdad.

\section{- Bolivia (2006-2014)}

La economía boliviana se construye sobre la extracción y exportación de sus recursos naturales, siendo las actividades económicas más relevantes la minería y la extracción de gas natural ${ }^{7}$. El inicio de la presidencia de Evo Morales en 2006 estuvo marcado por la nacionalización de los hidrocarburos, a través de un decreto presidencial, que abrió una nueva etapa de participación del Estado en la economía boliviana (WEISTBROT; RAY; JOHNSTONE, 2009, p. 12; VARGAS SUÁREZ, 2009, p. 18 y ss).

Históricamente la economía nacional se caracterizó por la dependencia a un patrón de desarrollo monoproductor, en el que se recuerda siendo el periodo 2009-2014 como el auge de la explotación hidrocarburífera (VARGAS SUÁREZ, 2009, p. 18-20). Tal como sostiene Gray Molina (2006, p. 65-6), en Bolivia ha persistido un mismo patrón, administrado desde distintos modelos (privado o de gestión estatal), que concentra la economía nacional en la exportación de pocos productos sin procesamiento o agregado de valor.

A pesar de la dependencia a la explotación hidrocarburífera, la economía boliviana creció a una tasa anual promedio del 4,9\% debido a los altos precios de las materias primas y una política macroeconómica prudente durante el periodo 2004-2014 (BANCO MUNDIAL, 2016c). Luego y con un contexto internacional más desafiante, el crecimiento del PBI se redujo de un pico de 6,8\% en 2014 a un 4,8\% en 2015. El efecto de la caída de los precios internacionales de las materias primas fue contenido por políticas que aprovecharon la bonanza acumulada los años anteriores (BANCO MUNDIAL, 2016c). Este panorama económico tuvo lugar en una sociedad fragmentada por la diversidad cultural y sus distintas visiones sobre las vías de desarrollo del país. Las disidencias estuvieron geográficamente marcadas hacia el interior del Estado e impulsaron movimientos de autonomía departamental durante la primera gestión de Morales (2006-2010) (HARMES-LIEDTKE; DELLAVEDOVA, 2013, p. 14), sobre todo en aquellos departamentos cuyo desarrollo económico se vio amenazado por las políticas nacionales.

A finales de 2014 y en un contexto de mayor cohesión social, el PBI de Bolivia se elevó a 33 mil millones de USD, en una economía cuyos principales socios comerciales Brasil, Argentina, Estados Unidos y China (BANCO MUNDIAL, 2016c). Sin embargo, la economía boliviana es aún muy sencilla y se ubica claramente en la periferia, con poco saldo exportable, más allá del gas, la minería y de la producción ilícita derivada de la coca (DOMINGUES, 2012, p. 35).

Con miras a consolidar su posición como exportador de gas natural a la región, Bolivia requiere aunar esfuerzos con el sector privado para aumentar las reservas probadas de gas (VARGAS SUÁREZ, 2009, p. 30-1). Pero además requiere atraer inversiones en sectores que

\footnotetext{
${ }^{7}$ Los metales de exportación más valiosos son: estaño (4ํ productor mundial), plata (11o productor mundial), litio y cobre. Los principales yacimientos mineros son: San Cristóbal (mina de plata de cielo abierto más grande del mundo), Mutún y el Salar de Uyuni (una de las principales reservas de potasio y litio del mundo). Además Bolivia cuenta con la segunda mayor reserva de gas natural de América del Sur (48 trillones de pies cúbicos), siendo su exportación a Brasil y Argentina la principal fuente de ingresos del país (BANCO MUNDIAL, 2016c).
} 
tradicionalmente han sido menos atractivos para los inversionistas privados, incluyendo minería, agricultura y manufactura (BANCO MUNDIAL, 2016c).

Entonces se observa que tanto Argentina como Bolivia y Chile son economías exportadoras de commodities y a pesar de que en algunos casos presenten un PBI alto, se ubican claramente en la periferia puesto que en ellas predomina el sector primario y poseen escasa diversificación productiva, entendiendo que el desarrollo debe propiciar una mezcla de exportaciones más allá de los productos básicos y mercados abiertos con intervenciones calculadas (POLLOCK, 2006, p. 17-8; DOMINGUES, 2012, p. 49). El grado de subdesarrollo es distinto en cada caso dado la complejización interna y las particularidades de Estado, aunque en general es el subdesarrollo lo que los caracteriza, siempre definido a partir de una comparación con las economías de los países centrales (DOMINGUES, 2012, p. 55).

\section{SEGUNDA PERIFERIA: RELACIÓN ESTADO - UNIDADES SUBESTATALES}

La globalización y el proceso de transnacionalización de la economía propiciaron la apertura a la intervención de las unidades subestatales a través de gestiones de carácter internacional complementarias a las acciones del Estado que les permitan aprovechar las oportunidades del mercado internacional (FERRER, 1999, p. 52-4; DEL ARENAL, 2002 , p. 29-48). En tal sentido la globalización es entendida como un sistema de redes financieras, de comercio y de integración de cadenas de valor, que se profundiza a lo largo del tiempo bajo el efecto del avance de la ciencia y la tecnología (FERRER, 2010, p. 9), y desde el cual se forma el pensamiento hegemónico, funcional a los intereses del "centro" productivo (SUNKEL; PAZ, 1970, p. 37; PREBISCH, 1979, p. 176; FERRER, 2007, p. 433).

De manera tal que el mismo proceso globalizador que contribuye a la asignación y roles y funciones desde el centro hacia la periferia, manteniendo la estructura jerárquica es también el mismo sistema que propicia la apertura y participación de las unidades subestatales.

Ahora bien, ¿qué ocurre con las unidades políticas existentes en el interior de los Estados periféricos? ¿Se reproduce el modelo centro-periferia entre las unidades subestatales? ¿Cuáles son los condicionantes que definen la gestión internacional de las unidades subestatales? Los Estados en estudio (Argentina, Bolivia y Chile) son países en vías de desarrollo ${ }^{8}$ situados en la periferia del sistema internacional respecto de los grandes centros económicos y productivos, cuyas estructuras han reproducido las características del sistema hacia el interior de las fronteras nacionales, creando una doble periferia para algunas unidades subestatales. Para confirmar la existencia de ésta doble periferia, el análisis partirá de las condiciones ambientales y las estructuras económicas que determinan la relación centro-periferia a nivel subestatal.

\section{a. Las condiciones ambientales}

Al contrario de lo sostenido por los defensores de la globalización, la variable ambiental vinculada a la localización de la producción, los flujos de comercio y los aspectos socio-políticos

\footnotetext{
${ }^{8}$ La distinción Norte - Sur entre los países desarrollados y los países en vías de desarrollo ha marcado una división geográfica del desarrollo a partir de la década de los '60. Tal división no tiene en cuenta sólo los criterios económicos sino también la asociación con determinados valores e ideologías, así el Norte se identifica como un grupo de países homogéneo, con poder en el contexto internacional que se distinguen por instituciones democráticas y economías de libre mercado mientras que el Sur, se identifica como un grupo heterogéneo de países que no han alcanzado un desarrollo económico caracterizado por el crecimiento y la industrialización (KRIEGER, 1993).
} 
del desarrollo es cada vez más determinante en el desarrollo (MONCAYO JIMÉNEZ, 2002, p. 1-3). La distribución territorial de los elementos modernos (industriales) y los elementos tradicionales que dentro de una economía nacional aportan al grado de homogeneidad o heterogeneidad de desarrollo de un Estado (BOISSIER, 2010, p. 40-1).

Entonces las actividades productivas de un Estado tienden a concentrarse en determinadas regiones o espacios geográficos lo que lleva a cuestionarnos, ¿ipor qué emergen en un mismo espacio un área dedicada a actividades primarias y las concentraciones urbanas de actividades industriales o terciarias? ¿Por qué no puede existir un desarrollo armónico en el territorio de un Estado? La respuesta tiene que ver primeramente con las condiciones físicas que brinda la geografía en los espacios donde las regiones se desarrollan (SUNKEL; PAZ, 1970, p. 63-4; MONCAYO JIMÉNEZ, 2000, p. 8-9). Así, el clima cálido, húmedo, y la riqueza natural propician el desarrollo de espacios geográficos aptos para las actividades productivas primarias como la agricultura, la ganadería, la explotación forestal, la pesca o la minería, mientras que en aquellas regiones menos favorecidas se concentran las actividades productivas secundarias y terciarias, como las manufacturas y los servicios (SUNKEL; PAZ, 1970, p. 62; CEPAL, 2012, p. 35-6).

Ahora bien, ¿cómo se visualiza este fenómeno hacia el interior de los Estados? En Argentina la pampa húmeda fue tradicionalmente el área geográfica de desarrollo agrícola y ganadero, las regiones del Noroeste y la Patagonia desarrollaron el área minera y energética, y el Nordeste se especializó en la pesca y explotación forestal, quedando para la región del centro las actividades industriales y de servicios. En Chile, la principal actividad económica es la minería y se desarrolló en la región Norte, dedicándose el centro y la región del Sur a la producción de manufacturas y servicios. En Bolivia la incipiente industria se desarrolla en los departamentos de La Paz y Santa Cruz de la Sierra, mientras que la principal actividad económica se basa en la extracción de recursos hidrocarburíferos que se producen en las regiones de la periferia como Tarija, Oruro y Beni.

\section{b. La estructura económica}

Las condiciones ambientales de Argentina, Bolivia y Chile han dotado a Jujuy, Tarapacá y Tarija de importantes recursos naturales en base a los cuales se han desarrollado, en mayor o menor medida. El acceso directo a las materias primas es una de las garantías del crecimiento económico para llegar al objetivo de la modernización, fin último de las economías latinoamericanas y sus unidades subestatales. Para alcanzar la modernización, las unidades subestatales de doble periferia (de aquí en más USDP's), requieren la disponibilidad de recursos propios que emplean según sus intereses, y en este sentido pueden contraponerse con los de las regiones centrales comprometiendo seriamente el desarrollo de las primeras (OVIEDO, 2012 , p. 137-8). Las economías latinoamericanas se han caracterizado por explotar sus recursos para obtener beneficios concretos a corto plazo $^{9}$, relegando su potencial de valor estratégico para un desarrollo sostenible a futuro (OVIEDO, 2012, p. 138).

Teniendo en cuenta las variables medioambientales y la estructura económica de Argentina, Bolivia y Chile, se analizarán los condicionamientos para el desarrollo que contextualizan a Jujuy, Tarija y Tarapacá y las emplazan en la doble periferia.

\footnotetext{
${ }^{9}$ El interés por los recursos naturales ha sido clasificado en cuanto a su alcance en: corto, mediano y largo plazo
} (OVIEDO, 2012, p. 138). 


\section{- Provincia de Jujuy (Argentina)}

Analizando las condiciones ambientales, la provincia de Jujuy se encuentra emplazada geográficamente en el Noroeste argentino en la región denominada NOA, limita al Norte con Bolivia y al Oeste con Chile y posee una superficie de $53.219 \mathrm{~km} 2$, la que representa el 2,7\% del territorio argentino (MECON, 2015).

La periferia argentina se corresponde con las provincias situadas al Noroeste y Noreste del Estado, de economías principalmente primarias y alejadas del acceso a los puertos, caracterizadas por su retraso económico y social respecto al resto del país. La región geográfica centro del Estado, denominada pampa húmeda, es el centro del sistema estatal y la zona geográfica donde se emplaza la provincia portuaria de Buenos Aires, con un tejido industrial muy diversificado, dentro del que son relevantes la industria alimenticia, la fabricación de productos químicos, la industria metalmecánica, la producción automotriz y la refinación de petróleo.

La provincia de Jujuy es, respecto a Buenos Aires, una unidad subestatal casi seis veces más pequeña en superficie y su población representa un cuarto de la población bonaerense. Geográficamente, Buenos Aires es el punto donde confluye una extensa red ferroviaria que se extiende hacia los principales centros productivos del país; mientras que Jujuy se emplaza en el extremo Norte de Argentina y comparte frontera con Bolivia y Chile aunque aún no ha logrado consolidar un tráfico comercial fluido hacia los puertos chilenos ni un comercio estable con Bolivia.

Jujuy posee una estructura económica con un fuerte predominio del sector primario, en el que se destaca la producción agropecuaria, siendo los principales cultivos la caña de azúcar, el tabaco y los cítricos (ARGENTINA, 2012). La minería es la segunda actividad primaria que se destaca a través de la explotación de plata y boratos. Respecto del sector secundario el mismo se centra en los derivados de la producción de azúcar, como ser la pasta para la producción de papel (MARTíNEZ; MEDINA, 2013 , p. 14-20). Las actividades terciarias más importantes son las que dependen de la administración pública, y en segundo lugar el comercio y los servicios que se localizan principalmente en la capital (GOLOVANEVSKY; SCHORR, 2013 , p. 15).

Los indicadores productivos de la provincia muestran una economía escasamente diversificada, con especialización de la producción primaria y con poca diversificación, siendo la agricultura y la minería las principales actividades (ARGENTINA, 2012, p. 13-6; MECON, 2015, p. 3-4,). Por otra parte y no menos preocupante es el hecho de que el sector terciario se ha identificado con la actividad que se desprende de la administración pública, donde el Estado provincial es el principal empleador alcanzando el 17,5\% de la Población Económicamente Activa (PEA) para el año 2015, absorbiendo en diferentes momentos pero de manera continua, los desequilibrios que se dieron en el mercado de trabajo (ARGENTINA, 2012, p. 12-3; GOLOVANEVSKY; SCHORRER, 2013, p. 22-5).

\section{- Departamento de Tarija (Bolivia)}

En cuanto a las condiciones ambientales, el Departamento de Tarija se ubica en el extremo Sureste de Bolivia, limitando al Norte con el departamento de Chuquisaca, al Sur con Argentina, al Oeste con el Departamento de Chuquisaca y al Este con Paraguay. Es una zona de valles y serranías que cubren una superficie de $37.623 \mathrm{~km}^{2}$ donde se asienta una población de 483.518 personas para el año 2014 (BOLIVIA, 2016). 
En el sistema estatal boliviano el centro económico productivo se identifica con el Departamento de Santa Cruz, situado en el extremo sureste de Bolivia y que por su extensión, es una de las unidades subestatales más grandes de Sudamérica (su superficie representa el $34 \%$ del territorio nacional). Este departamento ha reportado la mayor tasa de crecimiento económico del país durante los últimos 50 años, siendo sus principales actividades económicas la producción agropecuaria, forestal e hidrocarburífera. La evolución de la economía de Santa Cruz está fuertemente relacionada al incremento de la inversión privada que permitió no sólo aumentar el crecimiento del PBG y del PBI, sino también iniciar una mayor diversificación de la actividad productiva.

Pero a diferencia de Jujuy y Tarapacá, la situación de Tarija dentro de Bolivia no siempre fue periférica. Muy por el contrario, Tarija formó parte del conglomerado regional que lideró el crecimiento económico durante la década de los noventa, junto a los departamentos de Santa Cruz, Chuquisaca, Pando y Beni (HARMES-LIEDTKE; DELLAVEDOVA, 2013, p. 13-4). Con la llegada de Morales a la presidencia y las transformaciones sociopolíticas y normativas del nuevo modelo económico nacional ${ }^{10}$, se produjo un cambio en la redistribución de los ingresos nacionales hacia los departamentos ${ }^{11}$ y esto condujo a un periodo de constante tensión entre el gobierno departamental y el gobierno nacional.

En este escenario, el Departamento de Tarija presenta una estructura económica esencialmente agropecuaria en la que se destaca la producción de papa, quinua, maíz, trigo, cebada, frutas como durazno, ciruelo, damasco, vid, como así también la ganadería ovina, bovina y porcina (INSTITUTO NACIONAL DE ESTADÍSTICA DE BOLIVIA [INE], 2014, p. 13).

La explotación de petróleo crudo y gas natural contribuyeron a un proceso migratorio interno hacia los puntos petrolíferos que produjo un crecimiento desordenado del departamento y una dependencia a los ingresos provenientes de las regalías (CUBA ROJAS, 2006, p. 58-9). Durante la gestión de Evo Morales se modificó la distribución de los impuestos a la explotación hidrocarburífera, con el argumento de adecuar las asignaciones del impuesto directo a los hidrocarburos (IDH) a los lineamientos estratégicos establecidos en el Plan Nacional de Desarrollo (LASERNA, 2011, p. 18-20). Pero la magnitud en que se redujeron los recursos para las regiones productoras de hidrocarburos, principalmente Tarija y Santa Cruz, que a su vez estaban embarcadas en un proyecto de conformación de gobiernos autónomos condujo a continuas pujas políticas con el gobierno nacional (AHORA DIGITAL, marzo de 2015 ).

Los ingresos departamentales que dependían en buena medida de la explotación hidrocarburífera se vieron disminuidos por las medidas nacionales, a las que se sumó la caída del precio del petróleo, justo en el momento en que Tarija se encaminaba en sus primeros años de autonomía departamental (HARMES-LIEDTKE; DELLAVEDOVA, 2013, p. 14-5). A partir de entonces la retracción económica y la crisis financiera departamental llevaron a Tarija a sostener permanentes negociaciones con el gobierno central a fin de obtener autorizaciones a créditos

\footnotetext{
${ }^{10}$ El gobierno de Evo Morales, transforma el modelo de desarrollo económico nacional, se habla de una economía plural, solidaria y comunitaria bajo la concepción del Sumaj Kawsay o buen vivir. Este concepto de desarrollo se refiere a la complementariedad entre el acceso y el disfrute de los bienes materiales y la realización afectiva, subjetiva y espiritual en armonía con la naturaleza y en comunidad con los seres humanos (HARMES-LIEDTKE; DELLAVEDOVA, 2013, p. 13).

${ }^{11}$ La redistribución del impuesto directo a los hidrocarburos y las regalías desincentiva la generación de recursos propios en las unidades subestatales, por lo cual, afecta negativamente la competitividad y eficiencia del sector productivo regional (HARMES-LIEDTKE; DELLAVEDOVA, 2013, p. 14).
} 
nacionales e internacionales para obra pública e incentivar a la actividad agropecuaria local (GOBERNACIÓN DE TARIJA... 2017).

\section{- Región de Tarapacá (Chile)}

Por sus condiciones ambientales la región de Tarapacá se ubica en el Norte chileno a una distancia superior a 1.800 kilómetros de la capital nacional Santiago. La región posee una superficie de 42.225,8 km2, equivalentes al 5,6\% del territorio nacional, y limita al norte con las regiones de Arica y Parinacota, al Este con Bolivia, al Sur con la región de Antofagasta y al Oeste con el océano Pacífico. La economía de la región se basa principalmente en la extracción de recursos naturales, especialmente la minería y la pesca comercial (CHILE, 2015b , p. 3-4).

En Chile la región económicamente central se corresponde con el centro geográfico del Estado y se identifica con la región Metropolitana de Santiago. Esta región es en superficie la más pequeña de todo Chile y la que no posee salida directa al océano Pacífico, no obstante ello, es la más habitada y la de mayor producción de bienes y servicios, presentando además la concentración industrial más alta del país del sector secundario o de transformación (INE, 2013, p. 13). Esto se explica por las mejores condiciones para el desarrollo industrial que ofrece la región: gran concentración de población, personal calificado, buenas vías de acceso para la entrada de materias primas y la salida de la producción, y abastecimiento de energía.

Históricamente la estructura económica de Tarapacá se desenvolvió alrededor de la explotación del salitre y cobre. No obstante, el sector económico más dinámico es el pesquero en donde las producciones de harina y aceite de pescado representan el $50 \%$ y el $60 \%$ del total nacional (AGENCIA REGIONAL DE DESARROLLO PRODUCTIVO, 2014, p. 8-9). Actualmente, la pesca industrial genera el mayor aporte al PBG con un 26\%, siendo lquique es el mayor puerto pesquero de Chile. Por último, la industria manufacturera está poco desarrollada y representa el 5\% del PBG, su mayor esfuerzo está en los astilleros, maestranzas, fábricas de repuestos e implementos de pesca, que sirven a la industria y flota pesquera (AGENCIA REGIONAL DE DESARROLLO PRODUCTIVO, 2014, p. 11-2).

En cambio, la Región Metropolitana concentra la mayor cantidad de industrias del país, aportando el 51\% del PIB nacional en este rubro (INE, 2013, p. 38-9). La industria de productos alimenticios, textiles, química y tabaco son las más representativas. Las actividades terciarias o de servicios se relacionan con la construcción, el comercio, transporte y comunicaciones, servicios financieros, administración pública, comercio, turismo, electricidad, gas y agua, entre otras. Además, la región se distingue a diferencia de otros territorios, por la productividad de sus tierras, hecho que le ha posibilitado desarrollar cultivos agropecuarios con rendimientos superiores al promedio nacional.

Entonces se puede establecer que la zona centro del sistema estatal chileno coincide con las regiones geográficamente ubicadas en el centro del coincidente con la Región Metropolitana de Santiago. En este punto, se combinan un gran número de industrias con las tierras que mayor índice de productividad concentran para la producción primaria, lo cual posibilita un entramado económico más diversificado que otras regiones (INE, 2013, p. 38-41).

Por otro lado, la región Norte de Chile es históricamente conocida por su riqueza minera y la aridez de sus suelos (AGENCIA REGIONAL DE DESARROLLO PRODUCTIVO, 2014, p. 15-6). En este campo la economía de Tarapacá resalta en la producción minera pero sobre todo en 
los recursos derivados de la explotación pesquera y la actividad portuaria en donde los duros factores ambientales no permiten el desarrollo agropecuario para satisfacer el mercado interno (AGENCIA REGIONAL DE DESARROLLO PRODUCTIVO, 2014, p. 8-9). Estos hechos no permiten una mayor diversificación de la economía regional, no obstante la región ha podido aprovechar las condiciones internacionales para maximizar los beneficios de sus recursos.

\section{CONCLUSIONES: HACIA UNA CONCEPTUALIZACIÓN DE LA DOBLE PERIFERIA}

El orden internacional proporciona un marco de referencia para el desarrollo de cada Estado. En este sentido se adhiere a la idea de Sunkel acerca del desarrollo como un proceso histórico global en el que el desarrollo y el subdesarrollo constituyen el dualismo centro-periferia. Este fenómeno se expresa geográficamente a través de la diferenciación entre áreas geográficas industriales y desarrolladas que son los "centros", y otras áreas geográficas subdesarrolladas, llamadas "periféricas".

La distinción entre centros y periferias guarda sus orígenes en elementos históricos de carácter exógeno y endógeno a cada unidad política. El elemento exógeno radica en el hecho que al inicio de su despegue, las economías periféricas como las latinoamericanas estaban relativamente atrasadas respecto de la economía y la potencia hegemónica. Para Argentina, Bolivia y Chile el elemento exógeno se remonta a su momento de colonia española. En cuanto al elemento endógeno, los estructuralistas hicieron hincapié en las condiciones internas que fueron decisivas para que los Estados centrales generaran un progreso técnico y lo difundieran en su tejido productivo. Este cúmulo de condiciones internas necesarias para el desarrollo fueron lo que Aldo Ferrer denominó "densidad nacional"12 y que en los casos analizados presenta debilidades tales como administración descuidada de los recursos disponibles, liderazgos políticos personalistas (Argentina y Bolivia), inestabilidad gubernamental ante crisis económicas y la falta de definición de un modelo de desarrollo propio sostenido en el tiempo.

Como consecuencia, el centro ejerce la dominación del sistema en virtud de su capacidad endógena de crecimiento, y tal relación de dominación se aplica tanto entre países como dentro de un país.

Como Estados periféricos, Argentina, Bolivia y Chile han reproducido en el interior de sus fronteras ese mismo sistema de relación centro-periferia, organizando el territorio nacional en áreas centrales de producción industriales y desarrolladas, y otras áreas periféricas, de producción primaria y poco diversificada, que responden a los intereses de las primeras. De manera tal que las unidades subestatales periféricas de un Estado periférico se encuentran en una situación de doble dependencia, son unidades subestatales de doble periferia: del Estado del cual forman parte y del sistema internacional.

El problema del desarrollo de la doble periferia en las unidades subestatales aparece así como la necesidad de superar el estado de doble dependencia, transformando las potencialidades del territorio para obtener mayor capacidad autónoma de crecimiento que permita satisfacer los objetivos del grupo social. En otras palabras, el desarrollo de una unidad política y geográfica significa lograr una creciente eficacia en la manipulación de su medio ambiente natural, así

\footnotetext{
${ }^{12}$ Entre los elementos que conforman la densidad nacional, Ferrer estudia: la integración de la sociedad, los liderazgos exitosos con estrategias de acumulación de poder, la movilización de los recursos disponibles dentro del territorio nacional y la estabilidad institucional y política a largo plazo (FERRER, 2007, p. 435).
} 
como de sus relaciones con otras unidades políticas y geográficas que les permitan superar sus condicionamientos estructurales.

Como puede observase, la globalización no ha cambiado la naturaleza del proceso de desarrollo, que sigue dependiendo de la capacidad de cada unidad política para crear conocimientos y estrategias que puedan incorporar en la actividad económica y en sus vinculaciones con otros actores. Desde la doble periferia, el desarrollo implica la organización, la creatividad y los recursos de cada unidad subestatal para contrarrestar los efectos de la dinámica centro-periferia y desarticular los efectos del doble centro. En este marco la gestión internacional es una de las estrategias que utilizan las USDP's para alcanzar este cometido.

\section{REFERENCIAS}

AGENCIA REGIONAL DE DESARROLLO PRODUCTIVO. Caracterización territorial de la región de Tarapacá. Santiago: Gobierno de Chile, 2014.

ARGENTINA. Ministerio de Producción de la Provincia de Jujuy. Programa de Servicios Agrícolas Provinciales (PROSAP). Estrategia provincial para el servicio agroalimentario. 2012. Disponible en: <http://www.prosap. gov.ar/webDocs/EPSA-JujuyResolucion156.pdf>. Acceso en: enero 2017.

Ministerio de Economía y Finanzas Públicas de Argentina (MECON). Secretaría de Política Económica y Planificación del Desarrollo. Ficha Provincial: Jujuy, oct. 2015. Disponible en: <http://www. mecon.gov.ar/peconomica/dnper/fichas_provinciales/Jujuy.pdf>. Acceso en: feb. 2017.

BANCO MUNDIAL. Overview Argentina. 2016a. Disponible en: <http://www.bancomundial.org/es/country/ argentina/overview>. Acceso en: oct. 2016.

Overview Chile. 2016b. Disponible en: <http://www.bancomundial.org/es/country/chile/ overview>. Acceso en: oct. 2016.

Overview Bolivia. 2016c. Disponible en: <http://www.bancomundial.org/es/country/bolivia/ overview>. Acceso en: oct. 2016.

BETETA, Hugo; MORENO-BRID, Juan Carlos. El desarrollo en las ideas de la CEPAL. Revista Economía UNAM, México, DF, v. 9, n. 27, p. 76-90, 2012.

BOLIVIA. Cámara Nacional de Comercio. Boletín de Comercio Exterior CNC-COMEX. Unidad de comercio, gerencia de marketing, servicios y relaciones institucionales, 2016 Disponible en: <http://box.cnc.bo/ cir2016/C2016-066_BOLETIN\%20COMEX\%20TARIJA.pdf>. Acceso en: enero 2017.

BOSIER, Sergio. Un marco para la paradiplomacia desde las estrategias de desarrollo regional: el retorno del actor territorial en un nuevo escenario. En: MAIRA, Luis. La política internacional subnacional en América Latina. Buenos Aires: El Zorzal, 2010.

BRICEÑO RUIZ, José; QUINTERO RIZZUTO, María; RUIZ DE BENITTEZ, Dyanna. El pensamiento estructuralista de la CEPAL sobre el desarrollo y la integración latinoamericana: reflexiones sobre su vigencia actual. Revista Aportes para la Integración Latinoamericana, La Plata, año XIX, n. 28, p. 1-34, jun. 2013.

CABOT, Diego. Agua potable y cloacas, el eje de un plan oficial de $\$ 20.000$ millones. La Nación, 23 enero 2017. Disponible en: <http://www.lanacion.com.ar/1978138-agua-potable-y-cloacas-el-eje-de-un-planoficial-de-20000-millones>. Acceso en: feb. 2017.

CÁMARA ARGENTINA DE COMERCIO Y SERVICIOS. Informe de actualización - comercio exterior. Buenos Aires, jul. 2016. Disponible en: <http://www.cac.com.ar/data/documentos/48_IACE\%20-\%20Julio\%20 de\%202016.pdf>. Acceso en: oct. 2016.

CENTRO MULTIDISCIPLINARIO DE STUDIOS BOLIVIANOS (CEMEB). La economía boliviana en la etapa post nueva CPE. 2015. Disponible en: <http://cebem.org/cmsfiles/publicaciones/La_economia_boliviana_en_ la_etapa_post_nueva_CPE.pdf>. Acceso en: oct. 2016. 
CHILE. Ministerio de Minería. Comisión Chilena del Cobre (COCHILCO). Competitividad de la Minería Chilena. Santiago de Chile: Gobierno de Chile, 2015a.

CHILE. Ministerio de Agricultura. Región de Tarapacá: información regional 2015. Santiago de Chile: ODEPA, 2015b. Disponible en: <http://www.odepa.cl/wp-content/files_mf/1426532095Tarapac\%C3\%A1marzo. pdf>. Acceso en: feb. 2017.

COCCARO, Pamela. Propagación de la crisis asiática en países latinoamericanos. Revista del Observatorio de la Economía Latinoamericana, n. 69, oct. 2006.

COMISIÓN ECONÓMICA PARA AMÉRICA LATINA Y EL CARIBE (CEPAL). Informe macroeconómico de América Latina y el Caribe. Santiago de Chile: CEPAL, 2012.

. La inversión extranjera directa en América Latina y el Caribe 1988. Santiago de Chile: CEPAL, 1998.

288p. Disponible en: <http://www.cepal.org/es/publicaciones/1153-la-inversion-extranjera-americalatina-caribe-1998>. Acceso en: oct. 2016.

CUBA ROJAS, Pablo. Bolivia: movimientos sociales, nacionalización y Asamblea Constituyente. Observatorio Social de América Latina (OSAL), Buenos Aires, año VII, n. 19, p. 55-64, enero-abr. 2006.

DABAT, Alejandro. El rumbo de la economía argentina bajo el kirchnerismo. Economía UNAM, Coyoacán, v. 9, n. 26, p. 43-67, 2012. Disponible en: <http://www.scielo.org.mx/scielo.php?script=sci_arttext\&pid= S1665952X2012000200002\&Ing=es\&nrm=iso>. Acceso en: enero 2017.

DEL ARENAL, Celestino. Mundialización, creciente interdependencia y globalización en las relaciones internacionales. Cursos de Derecho Internacional y Relaciones Internacionales de Vitoria-Gasteiz. Bilbao: Universidad del País Vasco, 2009.

DOMINGUES, José Maurício. Desarrollo, periferia y semiperiferia en la tercera fase de la modernidad global. 1. ed. Ciudad Autónoma de Buenos Aires: CLACSO, 2012.

FERRER, Aldo. Raúl Prebisch y el dilema del desarrollo en el mundo global. Revista CEPAL, Santiago de Chile, n. 101, p. 7-15, ago. 2010.

. Globalización, desarrollo y densidad nacional. En: VIDAL, Gregorio; GUILLÉN R., Arturo (Comp.). Repensar la teoría del desarrollo en un contexto de globalización. Homenaje a Celso Furtado. Buenos Aires: CLACSO, 2007.

. La globalización, la crisis financiera y América Latina: tiempos violentos. Neoliberalismo, globalización y desigualdad en América Latina. Buenos Aires: CLACSO, 1999.

FONDO MONETARIO INTERNACIONAL (FMI). Informe país Argentina n. 16/69. 2016. Disponible en: <https://www.imf.org/external/pubs/ft/scr/2016/cr1669.pdf>. Acceso en: feb. 2017.

GOBERNACIÓN DE TARIJA acude a préstamos bancarios, La. El Diario Nacional, 2017. Disponible en: <http://www.eldiario.net/noticias/2017/2017_01/nt170128/nacional.php?n=20\&-gobernacion-acudea-prestamo-bancario>. Acceso en: feb. 2017.

GOLOVANEVSKY, Laura; SCHORR, Martín. Estructura productiva y distribución del ingreso en Jujuy en la primera década del siglo XXI: el círculo vicioso del subdesarrollo. Pampa, Santa Fé, n. 9, dic. 2013. Disponible en:<http://www.scielo.org.ar/scielo.php?script=sci_arttext\&pid=S2314-02082013000100002\&lng=es\& nrm=iso $>$. Acceso en: feb. 2017.

GONZÁLEZ OCANTO, Ezequiel; MELÉNDES, Carlos. Crisis de gobernabilidad en América Latina: juegos verticales y horizontales. En: BARRERO ESCOBAR, Fredy; JOST, Stefan. Estabilidad democrática en América Latina. Bogotá: Editorial Fondo de Publicaciones Universidad Sergio Arboleda, 2010.

GRAN LOGRO económico del gobierno de Patricio Aylwin, El. El Mostrador, enero de 2017. Disponible en: <http://www.elmostrador.cl/mercados/2016/04/20/el-crecimiento-del-pib-durante-el-gobierno-depatricio-aylwin-fue-el-mejor-de-la-historia-de-chile/>. Acceso en: jul. 2017.

GRAY MOLINA, George. La economía boliviana más allá del gas. Revista América Latina Hoy, Salamanca, n. $43,2006$. 
HARMAS-LIEDTKE, Ulrich; DELLAVEDOVA, Martin. Desarrollo económico local en Bolivia: una aproximación a la "Cuarta Ola". Fondo Multilateral de Inversión del Banco Interamericano de Desarrollo, 2013. Disponibel en: <http://www.mesopartner.com/fileadmin/user_files/INFORME_MIF_RED-ES_ANEXO_BOLIVIA.pdf>. Acceso en: enero 2017.

INSTITUTO NACIONAL DE ESTADÍSTICA DE BOLIVIA (INE). Actualidad Estadística Departamental de Tarija. La Paz: Viceministerio de Defensa Civil; Estado Plurinacional de Bolivia, 2014.

INSTITUTO NACIONAL DE ESTADÍSTICAS DE CHILE (INE). Informe Económico Regional, Abril-Junio. Santiago de Chile: INE, 2013.

KRIEGER. Joel. The Oxford Companion to politics of the world. New York: Oxford University Press, 1993.

LASERNA, Roberto. Bolivia: bonanza exportadora y descentralización. Cochabamba: Centro de Estudios de la Realidad Económica y Social, 2011.

MARTíNEZ, Ricardo; MEDINA, Fernando. Recopilación de series históricas del producto bruto jujeño (1970/2011). Jujuy: Gobierno de la Provincia de Jujuy, 2013.

MONCAYO JIMÉNEZ, Edgard. Nuevos enfoques teóricos, evolución de las políticas regionales e impacto territorial de la globalización. Santiago de Chile: ILPES/CEPAL, 2002. (Serie Gestión Pública).

ORGANIZACIÓN PARA LA COOPERACIÓN Y EL DESARROLLO ECONÓMICO (OCDE). Estudios EConómicos de la OCDE: Chile- Visión General. México: OCDE, oct. 2013. Disponible en: <https://www.oecd.org/eco/ surveys/Overview\%20Chile\%20spanish.pdf>. Acceso en: feb. 2017.

OVIEDO, Eduardo Daniel. Puja de modernizaciones y relaciones económicas chino-latinoamericanas en un mundo en crisis. En: BERNAL-MEZA, Raúl; QUINTANAR, Silvia Victoria (Ed.). Regionalismo y orden mundial: Suramérica, Europa, China. Buenos Aires: Universidad Nacional del Centro de la Provincia de Buenos Aires; Nuevohacer, Grupo Editor Latinoamericano, 2012. p. 115-53.

POLLOCK, David. Raúl Prebisch: la esencia del líder. En: DOSMAN, Edgar J. (Ed.). Raúl Prebisch: el poder, los principios y la ética del desarrollo. 1. ed. Buenos Aires: BID-INTAL, 2006.

PREBISCH, Raúl. Hacia una teoría de la transformación. Revista de la CEPAL, Santiago de Chile, n. 96, p. 27-71, dec. 2008.

. Estructura socioeconómica y crisis del sistema. Santiago de Chile: CEPAL, 1979.

. El desarrollo económico de América Latina y algunos de sus principales problemas. Santiago de Chile: CEPAL, 1949.

SUNKEL, Osvaldo; PAZ, Pedro. El subdesarrollo latinoamericano y la teoría del desarrollo. 1. ed. México, DF: Siglo XXI Editores, 1970.

UGGLA, Fredrik. Bolivia: un año de vivir peligrosamente. Revista Ciencia Política, Santiago de Chile, v. 29, n. 2, p. 247-73, 2009.

VARGAS SUÁREZ, Rosío. La nacionalización de los hidrocarburos en la presidencia bolivianos en la presidencia de Evo Morales Ayma. Revista Latinoamérica, México, DF, n. 49, p. 11-34, 2009.

WALLERSTEIN, Immanuel. El moderno sistema mundial, la agricultura capitalista y los orígenes de la economía - mundo europea en el siglo XVI. México, DF: Siglo XXI, 1979.

WEISBROT, Mark; RAY, Rebecca; JOHNSTONE, Jake. La economía bajo el gobierno de Morales. Ensayos de Economía, Medellín, n. 20, abr. 2009.

\section{Sobre la autora:}

Stella Maris Juste: Licenciada en Relaciones Internacionales por la Universidad Católica de Santiago del Estero, Departamento Académico San Salvador y doctoranda en Relaciones Internacionales por la Universidad Nacional de Rosario. Es becaria doctoral del Consejo Nacional 
de Investigaciones Científicas y Técnicas (CONICET) y realiza su investigación en la Unidad Ejecutora de Ciencias Sociales y Regionales del CONICET y la Universidad Nacional de Jujuy. Su tesis doctoral se titula "La gestión internacional de las unidades subestatales de doble periferia. Los casos de Jujuy (Argentina), Tarija (Bolivia) y Tarapacá (Bolivia)". Actualmente se desempeña como docente adjunto en la cátedra Nuevos Actores de las Relaciones Internacionales de la Licenciatura en Relaciones Internacionales en la UCSE-DASS. E-mail: stellajuste@gmail.com 